\title{
Protozoa and digestive tract parameters in Blue wildebeest (Connochaetes taurinus) and Black wildebeest (Connochaetes gnou), with description of
} Entodinium taurinus n.sp.

\author{
Dirk G. Booyse ${ }^{1}$ and Burk A. Dehority ${ }^{2 *}$ \\ ${ }^{1}$ Department of Anatomy and Physiology, University of Pretoria, Private Bag X04, Onderstepoort 0110 \\ South Africa. Email: dirk.booyse@up.ac.za \\ ${ }^{2}$ Department of Animal Sciences, Ohio Agricultural Research and Development Center, The Ohio State \\ University, Wooster, OH 44691. E-mail: dehority.1@osu.edu. ${ }^{*}$ Corresponding author.
}

\begin{abstract}
Rumen contents from four blue wildebeest (Connochaetes taurinus) and six black wildebeest (Connochaetes gnou) were collected from two locations during two winter culling seasons. A total of 16 species of protozoa were found in blue wildebeest with Dasytricha ruminantium, Opisthotrichum janus and Ostracodinium gracile occurring in all four animals. In black wildebeest, 23 species of protozoa were observed with only Diplodinium bubalidis f. bubalidis and Ostracodinium damaliscus being present in all animals. In the blue wildebeest, the total number of species in an individual animal varied from $9-11$ and in the black wildebeest, the number ranged from $4-14$ species per animal. Concentrations of cells per $\mathrm{ml}$ ranged from 1110 to 5880 in the blue wildebeest and 3120 to 6240 in the black wildebeest. This study is the first report on protozoa species in the blue and black wildebeest. A new species of Entodinium is described, Entodinium taurinus n. sp., observed in the rumen contents of three blue wildebeest. Several physical parameters of the
\end{abstract}


digestive tract were also measured, including distribution, $\mathrm{pH}$, temperature and density of gastrointestinal contents in different sections of the total tract. In vitro gas production was estimated for rumen, cecum and colon contents.

Keywords: Blue wildebeest, Black wildebeest, Connochaetes gnou, Connochaetes taurinus, Entodinium taurinus n. sp., protozoa

\section{Introduction}

There are two species of wildebeest in Africa, The Blue wildebeest (Connochaetes taurinus), sometimes known as the common wildebeest, and the Black wildebeest (Connochaetes gnou) or White-tailed gnu. Both species have been described by Hofmann and Stewart (1972) as fresh grass grazers who require a source of water daily. Because of their blunt mussels both species are able to graze short green grass (Estes 1991). However, according to observations by game rangers, the black wildebeest differs slightly from the blue wildebeest in that they tend to prefer grazing on the taller forages. Dehority and Odenyo (2003) previously reported protozoa concentrations and generic distribution in two blue wildebeest from Kenya. However, no previous reports could be found on the species composition of rumen protozoa in either species of wildebeest.

\section{Material and methods}

\section{Animals}

Two blue wildebeest (Connochaetes taurinus) were harvested from the Ruimte Game Reserve $150 \mathrm{Km}$ north of Pretoria (24²3' $\left.20.47^{\prime \prime S}, 2^{\circ} 01^{\prime} 43.57^{\prime \prime E}\right)$. Two additional Blue wildebeest and 6 Black wildebeest (Connochaetes gnou) were collected from the Rietvlei Game Reserve 50Km south of Pretoria (2552' 41.17"S, 28¹6' 17.83"E). All animals were 
adult males, harvested during a controlled winter culling. After killing, the animals were weighed and their digestive tracts removed and separated into different anatomical sections by ligation (rumen, omasum, abomasum, small intestine, cecum, colon, spiral colon and transverse colon and rectum).

\section{Measurements}

Weight of organ contents was determined by weighing the organ full and empty (to the nearest $0.1 \mathrm{~g}$ ), using a Mettler PJ4000 electronic balance; $\mathrm{pH}$ of the contents was measured with a portable, battery-powered $\mathrm{pH}$ meter (Eutech, model EC-PH-10/01N); temperature of the contents was measured by inserting an electronic thermometer into the middle of the organ contents,

\section{Fermentation}

Separate $200 \mathrm{ml}$ samples of ingesta were obtained from the rumen, cecum and colon. Each sample was placed in a $250 \mathrm{ml}$ glass bottle fitted with a rubber stopper. A 20 gage stainless steel needle, to fit a $10 \mathrm{ml}$ glass syringe, was inserted through the stopper. The bottles were incubated in water-bath at $39^{\circ} \mathrm{C}$ and gas production was measured every minute for 45 minutes by displacement of the syringe plunger. The weight of each sample was estimated after the fermentation.

\section{Protozoa}

Handfuls of the rumen or cecum contents were taken at random and the fluid squeezed out by making a fist with the thumb pointed downward so the fluid could run down into a container. This was repeated until a $200 \mathrm{ml}$ sample was obtained from each organ. Due to the fine particle size of colon contents, a 40ml container was used to randomly scoop up samples until the $200 \mathrm{ml}$ volume was reached. One hundred $\mathrm{ml}$ of $70 \%$ ethanol was added to each of the $200 \mathrm{ml}$ samples for preservation. 
In the laboratory, a $10 \mathrm{ml}$ subsample was taken from each of the protozoa samples with a $1 \mathrm{ml}$ pipette, $1 \mathrm{ml}$ at a time until $10 \mathrm{ml}$ was acquired. Two drops of Brilliant Green Stain were added and the sample was allowed to stand overnight. Using a finnpipet, a $0.25 \mathrm{ml}$ aliquot of the $10 \mathrm{ml}$ stained sample was dropped onto a microscope glass slide, and fitted with a cover slip. Counts and species identifications were made using a standard light microscope. Results of the counts were multiplied by 4 to give the counts per $\mathrm{ml}$ of the preserved sample and then by 1.5 to give counts per $\mathrm{ml}$ of original fluid.

\section{Results}

\section{Animals}

Body weights for the four blue wildebeest varied from 143 to $360 \mathrm{Kg}$, averaging $262 \pm 90$ $\mathrm{Kg}$. The range of body weights in the six black wildebeest was quite narrow, 241-261 Kg, with an average weight of $252 \pm 10 \mathrm{Kg}$.

\section{Physical and Physiological Parameters}

The average weight of gastrointestinal contents in four blue wildebeest and four black wildebeest is given in Table 1, along with the percentage distribution in each of the eight sections of the tract, i.e., from the rumen to the rectum. Most of the contents were found in the rumen, $76-84 \%$ in the blue and black wildebeest, respectively. The next highest percentage was in the small intestine; however, values were less than $10 \%$.In general, $\mathrm{pH}$ varied from about 6.0 in the rumen and omasum, falling to approximately 4.0 in the abomasum and increasing back to around neutrality (7.0) down the rest of the tract (Table 1). Temperature of the contents was also measured, and was found to show an overall gradual decrease from the rumen to the rectum.

Density of the contents was measured in all organs except the omasum and abomasum, and ranged from $0.57-0.96$, with one exception, 1.14 in the small intestinal contents from the 
Table 1. Physical and physiological parameters of the gastrointestinal tract of the blue and black wildebeest

\begin{tabular}{|c|c|c|c|c|c|c|c|}
\hline $\begin{array}{l}\text { Total weight } \\
\text { (g) }\end{array}$ & Rumen & Omasum & $\begin{array}{c}\text { Abomasu } \\
\mathrm{m}\end{array}$ & $\begin{array}{c}\text { Small } \\
\text { intestine }\end{array}$ & Cecum & Colon & $\begin{array}{l}\text { Spiral } \\
\text { colon }\end{array}$ \\
\hline
\end{tabular}

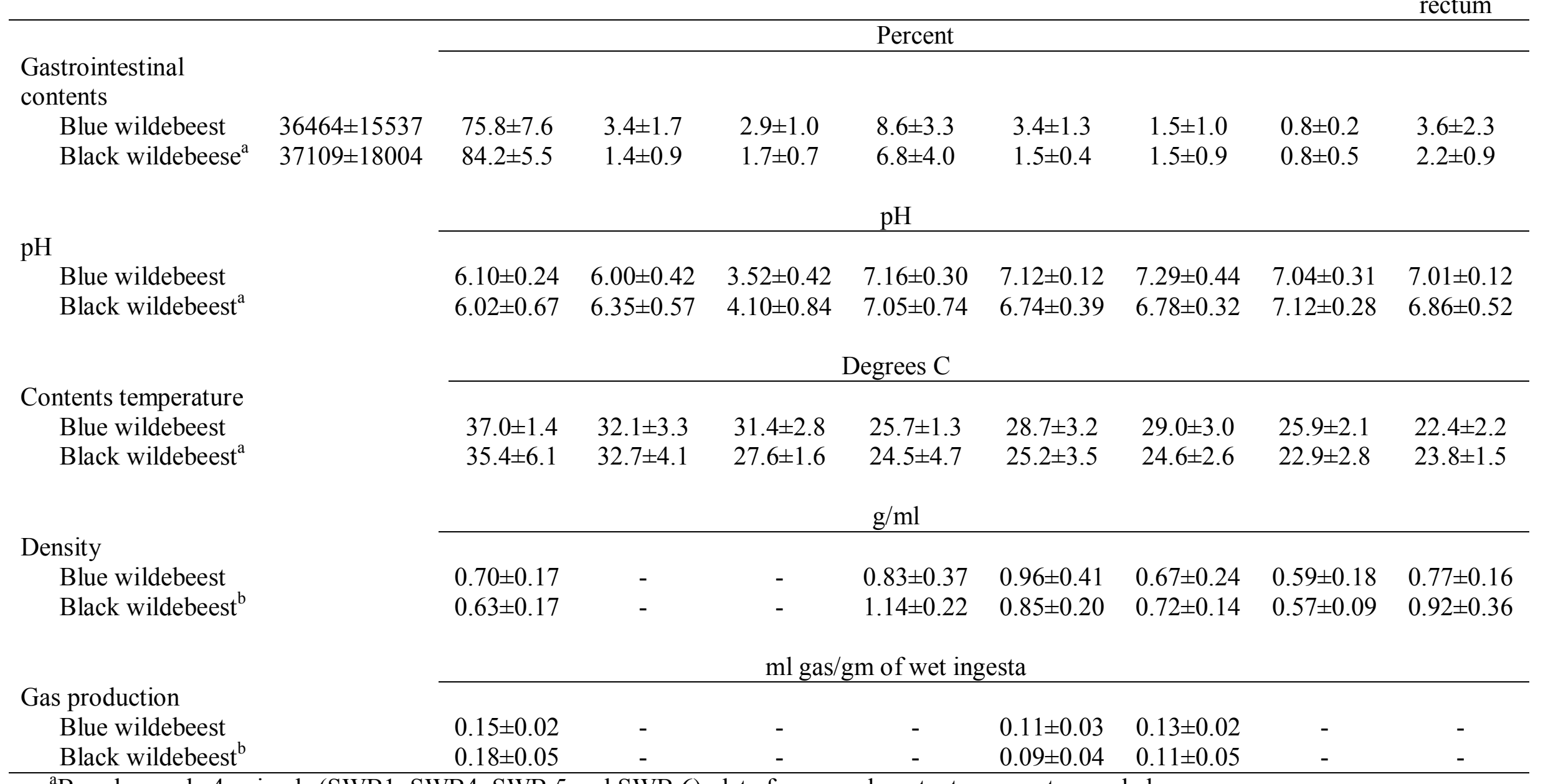

${ }^{\mathrm{a}}$ Based on only 4 animals (SWB1, SWB4, SWB 5 and SWB 6), data for omasal contents was not recorded.

${ }^{\mathrm{b}}$ Based on data from all 6 animals. 
black wildebeest (Table 1). Gas production, measured with ingesta from the rumen, cecum and colon, was slightly greater with the rumen contents, but relatively low in all three sites.

No statistical differences were found between the species for any of the above parameters.

\section{Protozoa}

Total protozoa concentrations in rumen fluid ranged from 1110 to 5880 per $\mathrm{ml}$ in blue wildebeest and from 3120 to 6240 per $\mathrm{ml}$ in black wildebeest (Table 2). No ciliate protozoa were found in either cecum or colon fluid.

Sixteen different species of protozoa were identified in the rumen of blue wildebeest, with Dasytricha ruminantium, Ostracodinium gracile and Opisthotrichum janus occurring in all 4 animals. Twenty species were found in black wildebeest, with only Diplodinium bubalidis $\mathrm{f}$. bubalidis and Ostracodinium damaliscus common to all 6 animals (Table 2). Entodinium nanellum, E. parvum, E. simplex, Diplodinium bubalidis f. aspinosum, Eudiplodinium kenyensis, Ostracodinium tenue, O. trivesiculatum, and Enoploplastron triloricatum and were found only in black wildebeest while Entodinium longinucleatum, E. taurinus n. sp., Metadinium affine and Epiplastron africanum were found only in blue wildebeest. The number of species occurring in an individual animal varied from 9-11 in blue wildebeest and 4-14 in black wildebeest.

A new species of Entodinium was observed in the rumen fluid of three blue wildebeest, and a description of this new species is given below. All dimensions are given in $\mu \mathrm{m}( \pm$ standard deviation) and are based on measurements from 20 specimens.

Entodinium taurinus n. sp. (Figs. 1 and 2)

Description: Body slightly truncated in side view and teardrop shaped when viewed from the dorsal side; a long posterior spine on the ventral side and a short blunt to pointed lobe on the posterior dorsal side; body length $39 \pm 5$ (35-44); body width $21 \pm 2$ (19-24); posterior spine $21 \pm 4$ (18-25); L/W $1.85 \pm 0.29$ (1.32-2.25); macronucleus $15 \pm 2$ (13-17); macronucleus 
Table 2. Concentration and percent distribution of protozoa species in the rumen of the blue and black wildebeest.

\begin{tabular}{|c|c|c|c|c|c|c|c|c|c|c|}
\hline \multirow{5}{*}{$\begin{array}{l}\text { Subfamily } \\
\text { Genus } \\
\text { Species }\end{array}$} & \multicolumn{4}{|c|}{ Blue Wildebeest } & \multirow{2}{*}{\multicolumn{6}{|c|}{$\begin{array}{l}\text { Black wildebeest } \\
\text { Rietvlei }\end{array}$}} \\
\hline & \multicolumn{2}{|c|}{ Ruimte } & \multicolumn{2}{|c|}{ Rietvlei } & & & & & & \\
\hline & \multicolumn{4}{|c|}{ July } & \multicolumn{3}{|c|}{ July } & \multicolumn{2}{|c|}{ August } & \multirow[t]{2}{*}{ Sept. } \\
\hline & \multicolumn{2}{|c|}{2006} & \multicolumn{2}{|c|}{2007} & \multicolumn{5}{|c|}{2006} & \\
\hline & BWB1 & BWB2 & BWBR1 & BWBR2 & SWB1 & SWB2 & SWB3 & SWB4 & SWB5 & SWB6 \\
\hline Total protozoa per $\mathrm{ml} \times 10^{3}$ & 1.11 & 4.02 & 4.80 & 5.88 & 3.66 & 6.24 & 3.12 & 4.35 & 3.77 & 3.81 \\
\hline Dasytricha ruminantium & 16.2 & 29.8 & 13.8 & 12.2 & 4.9 & - & - & - & - & - \\
\hline $\begin{array}{l}\text { Entodiniinae } \\
\text { Entodinium }\end{array}$ & 10.8 & 17.9 & 18.8 & 22.4 & 21.2 & 18.3 & 0 & 9.0 & 13.6 & 7.8 \\
\hline E. caudatum & 5.4 & - & - & - & 1.6 & 7.7 & - & - & - & 3.1 \\
\hline E. dubardi & 5.4 & 10.4 & - & 1.0 & 9.8 & 2.9 & - & 9.0 & 8.0 & 4.7 \\
\hline E. exiguum & - & 1.5 & - & - & 3.3 & - & - & - & - & - \\
\hline E. longinucleatum & - & - & - & 6.1 & - & - & - & - & - & - \\
\hline E. nanellum & - & - & - & - & - & 1.0 & - & - & - & - \\
\hline E. parvum & - & - & - & - & 3.3 & 6.7 & - & - & - & - \\
\hline E. simplex & - & - & - & - & 1.6 & - & - & - & - & - \\
\hline E. taurinus n. sp. & - & 6.0 & 18.8 & 15.3 & - & - & - & - & - & - \\
\hline$E$ species (unknown) ${ }^{\mathrm{a}}$ & - & - & - & - & 1.6 & - & - & - & - & 5.6 \\
\hline $\begin{array}{l}\text { Diplodiniinae } \\
\text { Diplodinium }\end{array}$ & 37.8 & 29.9 & 63.7 & 58.1 & 73.8 & 81.7 & 98.0 & 83.6 & 78.5 & 58.3 \\
\hline D. bubalidis f. aspinosum & - & - & - & - & 6.6 & 3.4 & - & - & - & 3.1 \\
\hline D. bubalidis f. bubalidis & - & 17.9 & 13.8 & 19.4 & 9.8 & 28.8 & 59.6 & 37.2 & 42.2 & 27.6 \\
\hline Eudiplodinium & & & & & & & & & & \\
\hline E. gigantium & - & - & 1.2 & - & 3.3 & - & - & 2.8 & - & 1.6 \\
\hline E. kenyensis & - & - & - & - & 3.3 & - & - & - & - & - \\
\hline
\end{tabular}




Ostracodinium
O.damaliscus
O. gladiator
O. gracile
O. nanum
O. tenue
O. trivesiculatum

Metadinium affine

\section{Enoploplastron \\ E. garstangi \\ E. triloricatum}

Diplodiniinae species (unknown) $^{\mathrm{a}}$

$\begin{array}{cccc}- & 3.0 & - & 4.1 \\ 10.8 & - & 7.5 & 1.0 \\ 10.8 & 6.0 & 13.8 & 19.4 \\ 5.4 & - & 1.2 & 1.0 \\ - & - & - & - \\ - & - & - & -\end{array}$

23.0
3.3
21.3
4.9
-
-
-

$\begin{array}{ccccc}16.8 & 19.2 & 11.0 & 25.1 & 10.2 \\ 1.9 & - & 5.5 & 1.6 & 7.9 \\ 26.9 & 19.2 & 27.6 & 6.4 & - \\ - & - & - & - & 1.6 \\ - & - & - & - & 3.1 \\ 1.0 & - & - & - & - \\ - & - & - & - & - \\ & & & & \\ - & - & - & 3.2 & 1.6 \\ - & - & - & - & 1.6\end{array}$

5.4

35.1

10.8

24.3

$3.0 \quad 11.2$

2.0

1.6

2.9

\section{Epiplastron africanum}

Opisthotrichum janus

Total number of species ${ }^{b}$

$9 \quad 9 \quad 10$

11

14

10

4

7

7

12

\footnotetext{
${ }^{\mathrm{a}}$ Distorted cells could not be identified below the Family or genus level.

${ }^{\mathrm{b}}$ Unknown Entodinium or Diplodiniinae species not included in total number of species.
} 
located dorsally in the middle to upper portion of cell; micronucleus lies near the middle of the macronucleus on the ventral side; contractile vacuole lies at the anterior end and slightly displaced toward the right side of the cell; esophagus bends toward the macronucleus; cytoproct terminates between the posterior lobe and spine.

Type host: Connochaetes taurinus, Blue wildebeest, Republic of South Africa.

Habitat. Rumen

Occurrence: E. taurinus n. sp. constituted $6.0,15.3$ and $18.8 \%$ of the total ciliates in three of the four blue wildebeest sampled.

Etymology: Entodinium taurinus is named after the host in which it was found.

Remarks: E. taurinus is distinguished from previously described species by its long and thin ventral posterior spine. Fig. 1 is a line drawing of E. taurinus as viewed from the right side. Fig. 2 presents several photographs focused to show the distinguishing features of this species

\section{Discussion}

In general, values for the different parameters listed in Table 1 are fairly similar to those previously reported for the impala in South Africa (Booyse and Dehority, 2011). The relatively low gas production, particularly from rumen contents, is probably a reflection of the procedure. Depending on the time of sampling, the extent of fermentation is undoubtedly controlled by the amount of available substrate. In any further studies, it would be best to add substrate as described by el-Shazly and Hungate (1965), to provide an estimate of microbial concentration.

Rumen protozoa concentrations in this study were considerably lower than reported by Dehority and Odenyo (2003) from two blue wildebeest in Kenya. This difference could be related to season, in that the animals from Kenya were sampled in early spring when forage was readily available as compared to the present animals sampled during the winter. 


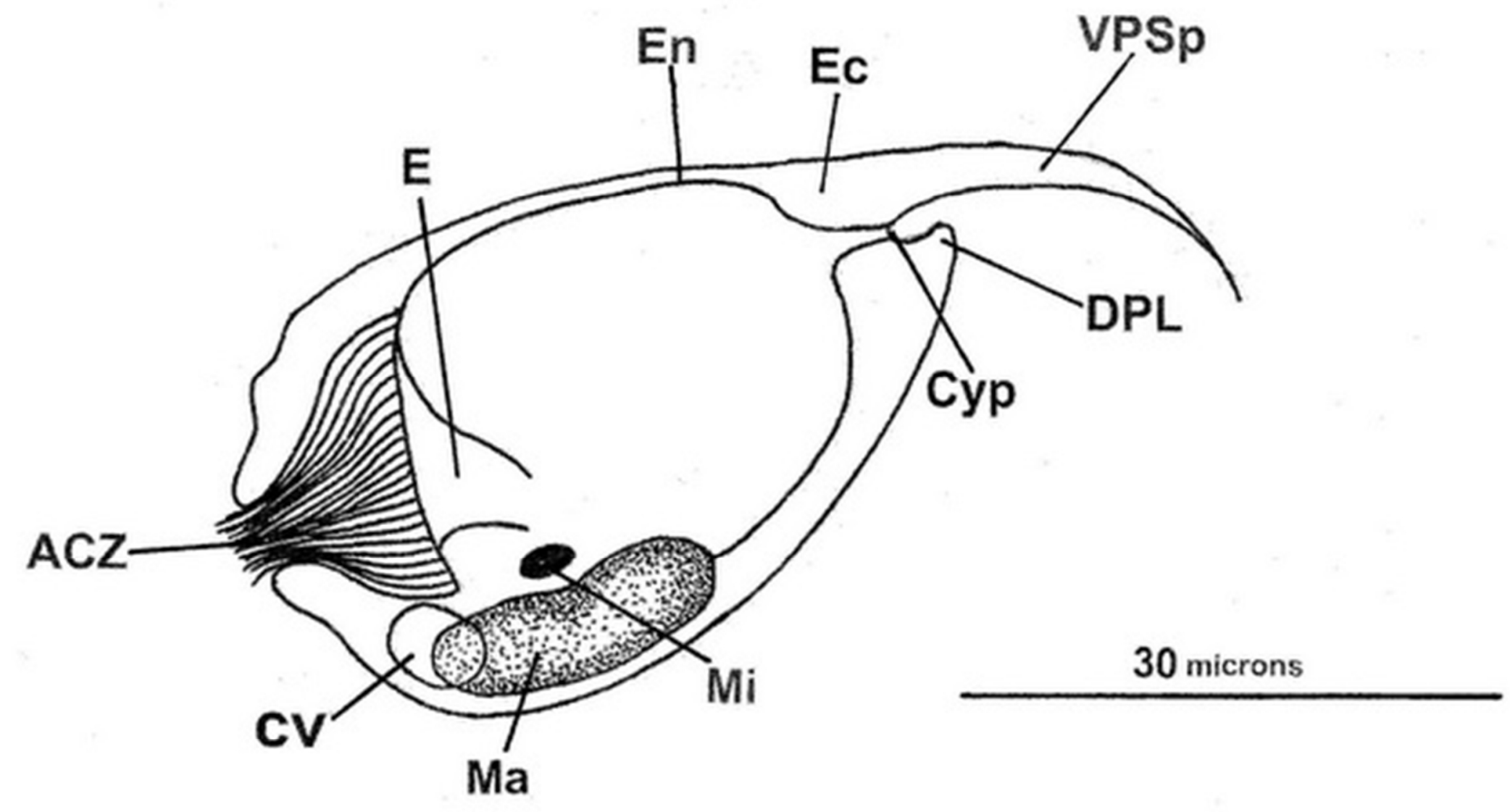

Fig. 1, Line drawing of Entodinium taurinus n. sp., view from the right side. Adoral ciliary zone (ACZ); Contractile vacuole (CV); Macronucleus (Ma); Micronucleus (Mi);Cytoproct (Cyp); Dorsal posterior lobe (DPL) Ventral posterior spine (VPSp); Ectoplasm (Ec); Endoplasmic sac (En); Esophagus (E). 


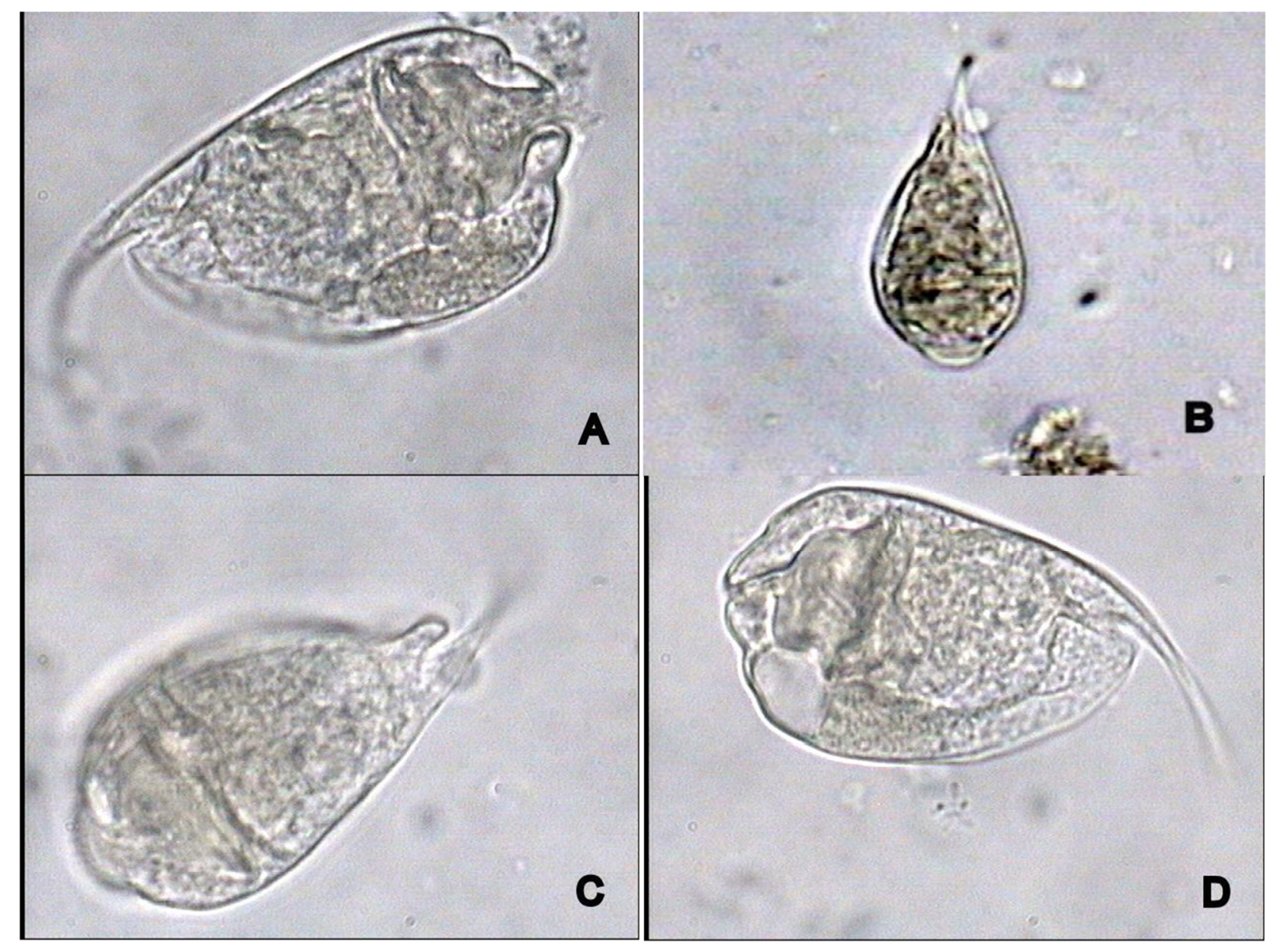

Fig. 2.Photographs of Entodinium taurinus n. sp. A.View from the left side showing macro- and micronucleus.

B. Dorsal view, showing both posterior projections and tear-shape of cell.

C. dorsal view, focused on posterior dorsal lobe.

D. View from the right side showing location of the contractile vacuole. 
The percentage Entodinium in this study, for all 10 animals, ranged from 0 to 22.4, with an average of $14.0 \pm 7.1$. This compares quite closely with the values 15.3 and 15.7 found by Dehority and Odenyo (2003) in the two blue wildebeest from Kenya. This low percentage of Entodinium differs markedly from most domestic ruminants fed on pasture (Dehority, 2003; Dehority and Orpin, 1997). The major portion of the ciliate population was in the family Diplodiniinae, particularly in the genus Ostracodinium. A similar pattern was found by Imai (1988) in zebu cattle living in Kenya. He postulated that this distribution was unique to grazing animals ingesting only roughage, since the Diplodiniinae species possess cellulolytic enzymes. Generic distribution in browsing or mixed feeding wild ruminants is generally very high in Entodinium, with values up to $100 \%$ in some animals (Dehority, 1995; Dehority and Odenyo, 2003; Dehority, Demaris and Osborne, 1999; Wilkinson and Van Hoven, 1976; Imai and Rung, 1990). Presumably the Entodinium species, with a shorter generation time, multiply rapidly utilizing starch and other readily available substrates (Dehority, 1998; 2004). Although the study by Dehority and Odenyo (2003) only identified protozoa to the generic level, all genera they reported were found in this study. In addition, species in two additional genera were observed, Metadinium affine and Epiplastron africanum.

Of particular interest was the much higher percentage of Diplodiniinae species in the black wildebeest and two blue wildebeest harvested at Rietvleil, $74.5 \pm 13.9 \%$, compared to $33.8 \pm 5.6 \%$ in the two blue wildebeest harvested at Ruimte $(P<0.01)$. In the animals at Rietvlei, most of the Diplodininiinae were species of Ostracodinium. Percentages of Ostracodinium species were 9 and 27 in the two wildebeest at Ruimte and ranged from 22.5 to 52.5 in those animals from Rietviel. Mean values were $18.0 \pm 12.7 \%$ and $35.7 \pm 11.5 \%$ in the wildebeest from Ruimte and Rietvlei respectively. The major difference in the blue wildebeest from the two sites was in the Ophryscolecinae, 35.1 and $22.4 \%$ from Ruimte and 3.8 and $7.1 \%$ from Rietvlei. 
Other than the occurrence of Dasytricha and Entodinium taurinus n. sp. There appeared to be little difference between the two species of wildebeest. Differences were more closely associated with location,

\section{References:}

1. Booyse, D. G., Dehority, B. A., 2011. Protozoa and digestive tract parameters of the impala. Onderstepoort Journal of Veterinary Research 78(1), Art. \#327, 5 pages. doi:10.4102/ojvr.v78i1.3278, 1

2. Dehority, B. A., 1995. Rumen ciliates of the pronghorn antelope (Antilocapra americana), mule deer (Odocoileus hemionus), white-tailed deer (Odocoileus virginianus) and elk (Cervus canadensis) in the northwestern United States. Archiv Fur Protistenkunde 146, 29-36.

3. Dehority, B. A., 1998. Generation times of Epidinium caudatum and Entodinium caudatum, determined in vitro by transferring at various time intervals. J. Anim. Sci. 76, 1189-1196.

4. Dehority, B. A., 2004. In vitro determination of generation times for Entodinium exiguum, Ophryoscolex purkynjei and Eudiplodinium maggii. J. Eukaryot. Microbiol. 51, 333-338.

5. Dehority, B. A., 2003. Rumen Microbiology. Nottingham University Press. Nottingham, UK.

6. Dehority, B. A., Odenyo, A. A., 2003. Influence of diet on the rumen protozoal fauna of indigenous African wild ruminants. J. Eukaryot. Microbiol. 50, 220-223.

7. Dehority, B. A., Demarais, S., Osborn, D. A., 1999. Rumen ciliate protozoa of whitetailed deer (Odocoileus virginianus), axis deer (Axis axis), sika deer (Cervus nippon) and fallow deer (Dama dama) from Texas. J. Eukayrot. Microbiol. 46,125-131. 
8. Dehority, B. A., Orpin, C. G., 1997. Development of, and natural fluctuations in rumen microbial populations. In: Hobson, P. N. and Stewart, C. S.(Eds.), The Rumen Microbial Ecosystems, Second edition, Blackie Academic and Professional, London, pp. 6-245.

9. el-Shazly, K., Hungate, R. E., 1965. Fermentation capacity as a measure of net growth of rumen microorganisms. Appl. Microbiol. 13, 62-69.

10. Estes, R., 1991. The Behaviour Guide to African Mammals, Including Hoofed Mammals, Carnivores, Primates. The University of California Press. Los Angeles, pp. 150-156

11. Hofmann, R. R., Stewart, D. R. M., 1972. Grazer or Browser: A classification based on the stomach- structure and feeding habits of East African ruminants. Mammalia, Paris, 36: $226-240$.

12. Imai, S., 1988. Ciliate protozoa in the rumen of Kenyan zebu cattle, Bos Taurus indicus, with the description of four new species. J. Protozool. 35, 130-136.

13. Imai, S., Rung,G., 1990. Rumen ciliates from the Mongolian gazelle, Procapra gutturosa. Jpn. J. Vet. Sci. 52, 1063-1067.

14. Wilkinson, R. C.,Van Hoven, W., 1976.Geographical distribution and population structure of springbok Antidorcas marsupialis rumen protozoa in southern Africa. Koedoe 19, 17-26. 